\title{
The Non-Linear Relationship between Electricity Consumption and Temperature in Taiwan: An Application for STR (Smooth Transition Regression) Model
}

\author{
Shu-Yi Liao1, Chi-Chung Chen ${ }^{1}$, Chia-Sheng Hsu ${ }^{2 *}$ \\ ${ }^{1}$ Department of Applied Economics, National Chung Hsing University, Taiwan \\ ${ }^{2}$ Institute of Economics, Academic Sinica, Taiwan \\ Email: sliao@nchu.edu.tw, mayjune@nchu.edu.tw, *victor9999951@hotmail.com
}

How to cite this paper: Liao, S.-Y., Chen, C.-C. and Hsu, C.-S. (2018) The Non-Linear Relationship between Electricity Consumption and Temperature in Taiwan: An Application for STR (Smooth Transition Regression) Model. Modern Economy, 9, 587-605.

https://doi.org/10.4236/me.2018.94038

Received: February 9, 2018

Accepted: April 6, 2018

Published: April 9, 2018

Copyright $\odot 2018$ by authors and Scientific Research Publishing Inc. This work is licensed under the Creative Commons Attribution International License (CC BY 4.0).

http://creativecommons.org/licenses/by/4.0/

\begin{abstract}
This study builds non-linear econometric models to analyze the effects of temperature on electricity consumption in Taiwan by using the smooth transition regression (STR) model and the monthly time-series data from 1983 to 2012. The empirical results indicate that there is a non-linear relationship between electricity consumption and temperature in Taiwan. Furthermore, all the six estimated threshold temperatures are between $25.364^{\circ} \mathrm{C}$ and $27.156^{\circ} \mathrm{C}$, and the average of threshold temperatures is $26.384^{\circ} \mathrm{C}$. It implies that Taiwan's electricity consumption has a non-linear growth if average temperature is higher than the threshold temperature. In addition, the estimated threshold temperature has policy implications for Taiwan's policy makers, meaning that the threshold temperature in this study can serve as a reference for framing policies of managing electricity demand in Taiwan.
\end{abstract}

\section{Keywords}

Smooth Transition Regression, Electricity Consumption, Threshold Temperature, Cooling Degree Days, ENSO

\section{Introduction}

Electricity consumption is contributed by many types of human activities, such as heating, air conditioning, lighting in both business and residential sectors, and major contributions come from operating equipment in industrial sectors. Whilst lighting and operating equipment might not be directly linked to climate change, heating and air conditioning have a direct impact on air temperature [1]. 
All the climate-change-related impacts on electricity demand and supply can be easily observed from the quantifiable effects of temperature on the use of heating and air conditioning, and these numbers are usually described by different measurements based on the concept of heating degree days (HDDs) and cooling degree days (CDDs).

HDDs is defined as the sum of negative deviations from the actually measured temperatures to the reference temperature (or base temperature) over a given time period; in contrast, CDDs indicates the sum of positive deviations from the average temperatures to the reference temperature over a given time period. The data frequency of the given time period is usually daily, weekly or monthly. The reference temperature is defined by the temperature level without additionally using electricity for heating or cooling. That is, if the air temperature is comfortable for humans, there will be less electricity consumption for heating or cooling.

The reference temperature can be generally considered to be $18.3^{\circ} \mathrm{C}\left(65^{\circ} \mathrm{F}\right)$ [2]. However, Parkpoom and Harrison [3] used $11.7^{\circ} \mathrm{C}\left(53^{\circ} \mathrm{F}\right)$ to be the reference temperature in Thailand; Howden and Crimp [4] determined $17.5^{\circ} \mathrm{C}\left(63.5^{\circ} \mathrm{F}\right)$ to be the reference temperature for Sydney; Ahmed et al. [5] proposed $14.3^{\circ} \mathrm{C}$ $\left(57.7^{\circ} \mathrm{F}\right)$ as the reference temperature for the State of New South Wales in Australia after their calculation; Zachariadis and Hadjinicolaou [6] employed $18^{\circ} \mathrm{C}$ $\left(64.4^{\circ} \mathrm{F}\right)$ and $22^{\circ} \mathrm{C}\left(71.6^{\circ} \mathrm{F}\right)$ respectively to be the reference temperature of HDDs and CDDs for the area of Mediterranean Europe. In sum, there could be different reference temperatures within different geographical regions.

Global warming could lead to increases in CDDs and decreases in HDDs, concluded by Benestad [7], whose report indicates that climate change could trigger more energy consumption due to air conditioning in the hot areas. De Cian et al. [8] used the panel data from 31 countries to investigate the relationship between energy consumption and variations in temperature. Their empirical results suggest that higher average temperature leads to more energy consumption during hot seasons in the warmer countries, but less energy is consumed during cold seasons in the colder countries.

Hekkenberg et al. [9] assessed the electricity demand pattern in the relatively temperate climate of the Netherlands. They used daily data over the period from 1970 to 2007 to investigate possible trends in the temperature dependence of electricity demand. Although the Netherlands has the minimum electricity demand in the summer months, however, their empirical results showed significant increases in the temperature dependence of electricity demand in the months of May, June, September, October and during the summer holidays. That is, their alarming result sends a signal to raise future expectations for additional peaks of electricity consumption in summer under the in the influence of climate change.

Moral-Carcedo and Vicéns-Otero [10] figured out that the relationship between electricity demand and temperature is nonlinear, and the nonlinearity is reflected on the threshold temperatures. They employed the threshold regression model (TR) and the logistic smooth transition regression (LSTR) model to build 
the relationship between electricity demand and temperature in Spain using daily data from 1995 to 2003.

In their research, they created the variable of working day effect to capture the variations of electricity demand caused by the activities in the industrial and commercial sectors as well as by the behaviors of households during holidays and on working days. Hence, they could eliminate those effects from electricity demand, then focus more on the pure effects of temperature on electricity demand. Their results showed that the threshold temperatures of the TR model are $15.5^{\circ} \mathrm{C}$ $\left(59.9^{\circ} \mathrm{F}\right)$ and $18.4^{\circ} \mathrm{C}\left(65.1^{\circ} \mathrm{F}\right)$, and the threshold temperature of the STR model is $18^{\circ} \mathrm{C}\left(64.4^{\circ} \mathrm{F}\right)$.

Bessec and Fouquau [11] investigated the relationship between electricity demand and temperature in 15 European countries over the period from 1985 to 2000 using monthly data. They applied a panel smooth transition regression (PSTR) model to describe the relationship between electricity demand and temperature in those countries and find threshold temperatures for those countries. In addition, in order to estimate the pure effects of temperature on electricity demand, they also followed Moral-Carcedo and Vicéns-Otero [10], and used dummy variables to represent summer holidays and time trends to filter out other source of electricity consumptions. Their results showed that the nonlinear pattern was more pronounced in the warm countries among the 15 European countries.

Lee and Chiu [12] used the PSTR model and took into account the potential endogeneity biases to examine the relationship between electricity demand and temperature of 24 OECD countries over the period from 1978 to 2004. They provided evidence of a $\mathrm{U}$-shaped relationship between electricity consumption and temperature of 24 OECD countries, and the threshold temperature is approximately $11.7^{\circ} \mathrm{C}\left(53^{\circ} \mathrm{F}\right)$.

In sum, to summarize the literature mentioned above, we can highlight two main findings. First, the relationship between electricity consumption and temperature shows nonlinearity in the past cases, so when establishing an econometric model for cases in Taiwan to estimate the effects of temperature on electricity consumption, we should consider possible nonlinear relationship between electricity consumption and temperature. Secondly, the threshold temperature has some policy implications, such as guidance for the management of electricity demand and supply, strategies for mitigating the impact of climate change on electricity.

To give an example of policy implications on electricity management, the Taiwanese government has introduced a policy since the year 2011 to save energy by asking public sectors to operate air conditioners only if the air temperature is higher than $26^{\circ} \mathrm{C}\left(78.8^{\circ} \mathrm{F}\right)$. In addition, once the real threshold temperature is found, it can be applied to computation of the data of CDDs in Taiwan to describe the patterns between temperature and electricity consumption both in the past and in the future. That is, if global warming leads to more temperature de- 
gree days, we should consider more power system expansion planning in Taiwan to meet the possible increases in electricity demand in the future. Therefore, we believe that it is worth further discussing how to model the real relationship between electricity consumption and temperature.

The objective of this study is to utilize the nonlinear econometric approach (STR model) to analyze the effects temperature has on electricity consumption in Taiwan. The estimated results of the STR model provide two mainly contributions to this study. First, we show the evidence of positively nonlinear relationship between electricity consumption and temperature in Taiwan. Secondly, we find that the average threshold temperature for Taiwan is about $26.384^{\circ} \mathrm{C}\left(79.3^{\circ} \mathrm{F}\right)$ over the period from 1983 to 2012. Furthermore, there are variations of threshold temperatures among different sample periods, and range of threshold temperatures lies between $25.364^{\circ} \mathrm{C}$ and $27.156^{\circ} \mathrm{C}$. The contributions of this study could be turned into policy implications for policy makers.

The remainder part of this study is organized as follows: Section 2 describes the data source, data descriptive and data processing. Section 3 presents the econometric methodology and the empirical model. Section 4 provides our empirical results. Section 5 is the conclusion of this study.

\section{Data}

\subsection{Data Source and Descriptive}

In this study, we use monthly time-series data which cover the period from 1983 to 2012. The original data of electricity consumption per capita (kWh) are collected from MOEABOE [13], and the gridded dataset of historical climate information from TCCIP [14] is used to compute the monthly average temperature $\left({ }^{\circ} \mathrm{C}\right)$ over the period from 1983 to 2012.

Table 1 displays the descriptive statistics on monthly average temperature in the different time period over 1983 to 2012. In Table 1, the mean temperature of the past three decades is between $21.997^{\circ} \mathrm{C}$ and $22.383^{\circ} \mathrm{C}$. The coldest month in a year are usually January and February, and the hottest month in a year, July and August. In addition, the mean temperature for summer (June, July and August) is between $27.127^{\circ} \mathrm{C}$ and $27.460^{\circ} \mathrm{C}$, and the stand deviation of temperature in

Table 1. Descriptive statistics on temperature.

\begin{tabular}{ccccccc}
\hline Time period & Mean & Min. & Max. & S.D. & Mean of Summer & S.D. of Summer \\
\hline $1983-1987$ & 22.127 & 14.326 (Feb.) & 28.948 (Jul.) & 4.711 & 27.395 & 0.716 \\
$1987-1992$ & 22.182 & 15.156 (Jan.) & 28.281 (Jul.) & 4.430 & 27.460 & 0.605 \\
$1993-1997$ & 21.997 & 14.285 (Feb.) & 28.064 (Jul.) & 4.473 & 27.127 & 0.647 \\
$1998-2002$ & 22.490 & 15.311 (Feb.) & 28.261 (Aug.) & 4.204 & 27.340 & 0.556 \\
$2002-2007$ & 22.383 & 14.786 (Jan.) & 28.929 (Jul.) & 4.452 & 27.397 & 0.840 \\
$2008-2012$ & 22.304 & 13.531 (Jan.) & 28.220 (Jul.) & 4.588 & 27.434 & 0.731
\end{tabular}

Notes: () refers to the month of the data value. 
summer is between $0.556^{\circ} \mathrm{C}$ and $0.840^{\circ} \mathrm{C}$, which indicates that we observe minor variations of temperature in summer in the past three decades in Taiwan.

Figure 1 shows the average electricity consumption and the average temperature, respectively. We can see that the month of the largest electricity consumption per capita in a year is August; however, the month of the highest temperature in a year is July, meaning the non-temperature impacts on electricity consumption should be considered. Therefore, in the Section 2.2, we filter out the effects of non-temperature factors on electricity consumption.

\subsection{Filtered Electricity Consumption}

In order to examine the pure effects of temperature on electricity consumption, we firstly remove the effects of other factors on electricity consumption [10] [11]. Especially, Bessec and Fouquau [11] indicated that three major components must be considered when we filter out the other effects affecting electricity consumption. The first component is the demographic trend, the second component is the technological trend, and the third component is the monthly seasonality related to the activity. However, our data of electricity consumption are divided by population, so we can say that our data of electricity consumption have removed the effects of demographic trends. Then, we follow Moral-Carcedo and Vicéns-Otero [10] as well as Bessec and Fouquau [11], the two last components will be filtered out from electricity consumption by employing Equation (1),

$$
E C_{t}=\beta_{0}+\beta_{1} t+\beta_{2} t^{2}+\beta_{3} t^{3}+\beta_{4} D+F E C_{t}
$$

where $E C_{t}$ represents the electricity consumption at time $t$; $t$ denotes the time trend; $D$ is a dummy variable. We define the value of July and August equal to one, and the values of other months are equal to zero. The dummy variable is used to remove the effects of summer holidays on electricity consumption [10]. $F E C_{t}$ stands for the filtered electricity consumption, and it is also the estimated

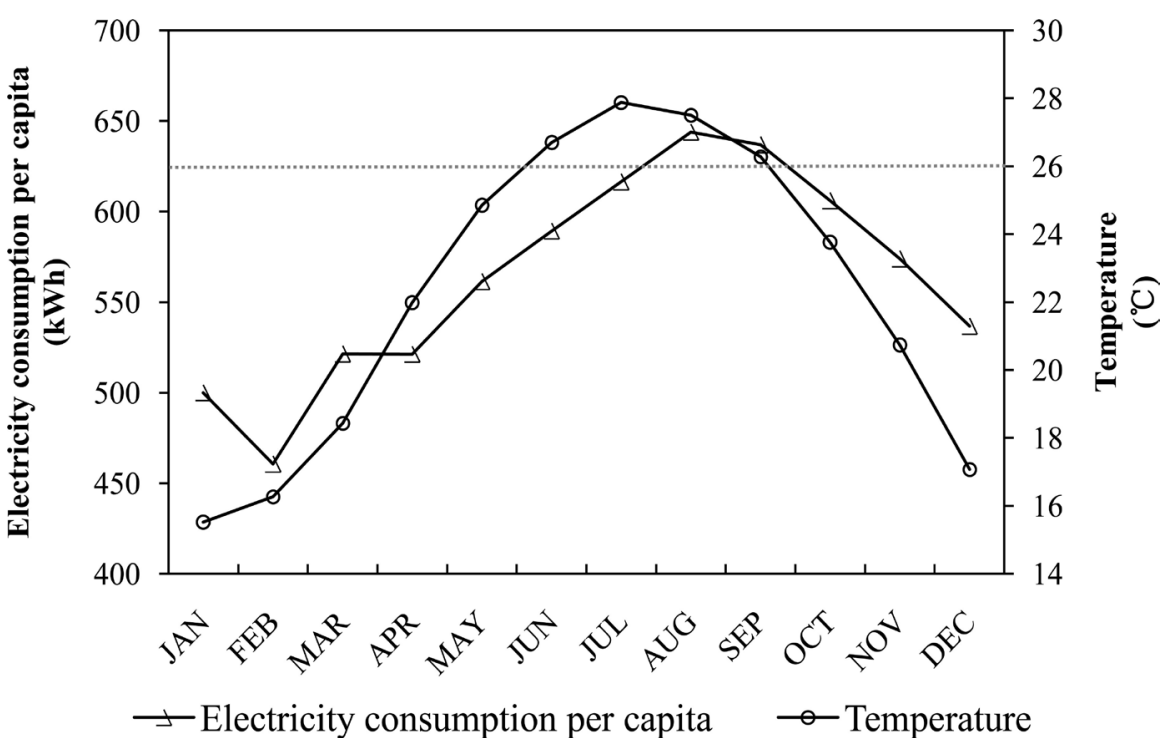

Figure 1. The average electricity consumption and average temperature (1983-2012). 
residual from Equation (1), and Table 2 shows the estimated result of Equation (1).

Figure 2 is the scatter plot of filtered electricity consumption and temperature over the period from 1983 to 2012 . We also repot a regression line between filtered electricity consumption and temperature with a polynomial of order three. However, we cannot see the U-shape relationship between electricity consumption and temperature in Figure 2. In Taiwan, people usually use more gas and oil products for cooking and heating in the cold seasons (from Oct. to Feb.), and air conditioner for cooling in summer, which is the reason for the non U-shape relationship between electricity consumption and temperature in Taiwan. However, although Figure 2 looks like there is a positive linear relationship between electricity consumption and temperature, we still believe that there could be a threshold temperature in the relationship between electricity consumption and

Table 2. The estimated result of filtered electricity consumption.

\begin{tabular}{cc}
\hline Parameter & Coefficient \\
\hline Constant & $188.238(11.021)^{* * *}$ \\
$t$ & $0.795(0.265)^{* * *}$ \\
$t^{2}$ & $0.012(0.002)^{* * *}$ \\
$t^{3}$ & $-0.001(0.000)^{* * *}$ \\
$D$ & $77.194(7.428)^{* * *}$ \\
Adj. $R^{2}$ & 0.950 \\
F-statistic & $1706.697^{* * *}$ \\
NO. of observation & 360 \\
\hline
\end{tabular}

Notes: 1) () stands for standard deviation. 2) ${ }^{\star * \star}$ refers to the significance level at $1 \%$.

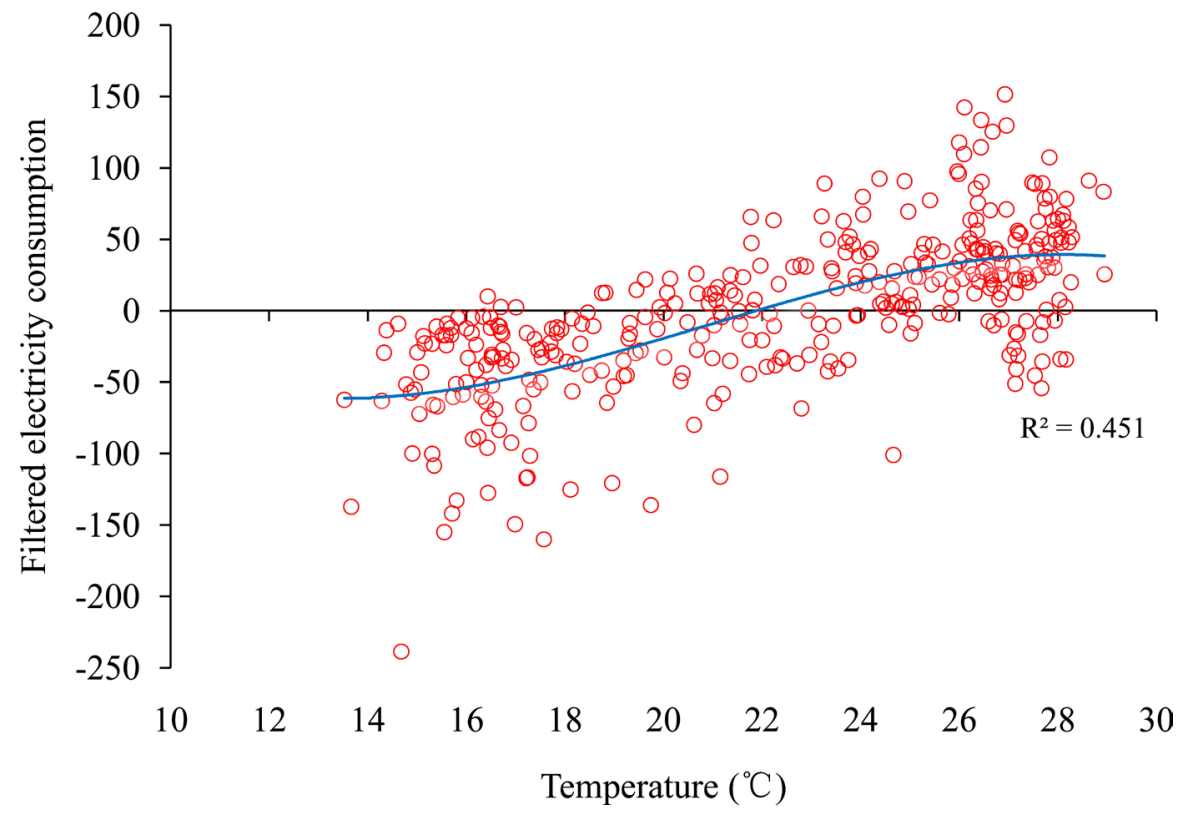

Figure 2. Filtered electricity consumption and temperature (1983-2012). 
temperature. At this stage, we will employ smooth transition regression models [15] to investigate whether the nonlinear relationship exists between electricity consumption and temperature in Taiwan or not.

\section{Methodology and Empirical Model}

This study employs the STR model to analyze the pure effects of temperature on electricity consumption in Taiwan. However, before the estimation of the STR model, we firstly have to test whether the time series data are stationary or not; that is, we have to conduct a unit root test for each set of time series data. Hence, we will introduce the methodology of unit root test which we have used for this study in the following section.

\subsection{Unit Root Test}

The stationary of time series data is usually examined by the Augmented and Dickey Fuller (ADF) test and Philips-Perron (P.P.) test in the past literatures, and these two tests were provided by Dickey and Fuller [16] and Philips and Perron [17], respectively.

However, both the ADF test and P.P. test have not considered the possibility of a structural break in the time series data. Therefore, to solve this problem, we employ the unit root test with structural breaks provided by Saikkonen and Lütkepohl [18] and Lanne et al. [19]. If there is a shift in the data generating process (DGP) of the level data, it should be taken into account in the unit root testing. The shift function $f_{t}(\delta)^{\prime} \varphi$ and deterministic trend will be included in the DGP of the time series $I_{t}$, such as Equation (2),

$$
I_{t}=\mu_{0}+\mu_{1} t+f_{t}(\delta)^{\prime} \varphi+\varepsilon_{t}
$$

where $\delta$ and $\varphi$ are unknown parameters; $\varepsilon_{t}$ is the error term generated by $\mathrm{AR}(\mathrm{p})$ process with possible unit root. Here, two types of shift function are applied for the unit root test in this study. The first type is a simple shift dummy variable $d_{1 t}$ with shift date $T_{B}$; if $t \geq T_{B}$, the dummy variable $d_{1 t}$ is equal to 1 ; on the contrary, if $t<T_{B}$, the dummy variable $d_{1 t}$ is equal to 0 . The difference in the shift function makes an impulse dummy, which can be seen as a rational function in the lag operator applied by $d_{1 t}$. Moreover, the actual shift term of impulse dummy is $\left[\varphi_{1}(1-\delta L)^{-1}+\varphi_{2}(1-\delta L)^{-1} L\right] d_{1 t}$, where $\delta$ is a scalar parameter between 0 and 1 ; and $\varphi=\left(\varphi_{1}: \varphi_{2}\right)$ is a two dimensional parameter vector.

Once a break point is fixed, Saikkonen and Lütkepohl [18] and Lanne et al. [19] suggested the unit root test (Equation (2)) could be estimated by the generalized least square (GLS) procedure under the null hypothesis of unit root. In addition, Lanne et al. [19] also provided the critical value for this unit root test.

\subsection{Smooth Transition Regression (STR) Model}

The STR model is widely used to describe the nonlinear relation of time series 
data. The univariate form of STR was proposed by Chan and Tong [20], subsequently developed by Luukkonen et al. [21] and Teräsvirta [15] [22]. Areosa et al. [23] further showed the estimation of STR models with endogenous variables. Hence, according to Teräsvirta [15], the STR model can be specified as Equation (3).

$$
y_{t}=\pi z_{t}+\theta z_{t} F\left(s_{t}, \gamma, c\right)+u_{t}
$$

where $t$ represents time dimension; $y_{t}$ is a dependent variable; $F\left(s_{t}, \gamma, c\right)$ represents the transition function with the transition variable $s_{t} ; \pi$ and $\theta$ represent the linear part of the model and nonlinear part of the model, respectively. $\gamma$ is a slope parameter which shows the speed of transition from one regime to another regime, and $c$ is also the extreme threshold of the transition variable. In the equation, $z_{t}=\left(y_{t-1}, \cdots, y_{t-p} ; x_{t}, x_{t-1}, \cdots, x_{t-q}\right), y_{t-p}$ indicates the optimal autoregressive term for $p$ lag lengths of dependent variable, and $x_{t-q}$ means the independent variable of $q$ lag lengths. $\pi$ and $\theta$ represent the linear part of the model and nonlinear part of the model, respectively. If $\gamma \rightarrow \infty$, the STR model will reduce to the threshold regression (TR) model, meaning that if the transition variable is larger than $c$, the transition function will be one. However, if the transition variable is smaller than $c$, the transition function will be zero. In addition, if $\gamma \rightarrow 0$, the STR model will change to a linear model.

Generally, the transition function usually can be distinguished into two types of function forms, namely, the logistic function and the exponential function. They are expressed as Equation (4) and Equation (5), respectively.

$$
F\left(s_{t}, \gamma, c\right)=\left[\frac{1}{1+\exp \left(-\gamma\left(s_{t}-c\right)\right)}-\frac{1}{2}\right]
$$

or

$$
F\left(s_{t}, \gamma, c\right)=\left[1-\exp \left(-\gamma\left(s_{t}-c\right)\right)^{2}\right]
$$

The first step of the STR estimation starts with examining whether there is a nonlinear relationship between the dependent variable and the transition variable or not. If the nonlinear relationship exists between the variables, then the second step of STR estimation will investigate the number of regime switch. Both of the two steps can be identified via the coefficient test on the following auxiliary regression, as Equation (6) shows:

$$
y_{t}=\beta_{0}^{\prime} z_{t}+\beta_{1}^{\prime} z_{t} s_{t}+\beta_{2}^{\prime} z_{t} s_{t}^{2}+\beta_{3}^{\prime} z_{t} s_{t}^{3}+\eta_{t}
$$

The null hypothesis of the linearity of the relationship between dependent variables and independent variables versus the alternative hypothesis of the nonlinearity of the relationship between dependent variables and independent variables can be examined by the null hypothesis of coefficient test as follows:

$$
H_{1}: \beta_{1}^{\prime}=\beta_{2}^{\prime}=\beta_{3}^{\prime}=0
$$

The test statistic of $H_{1}$ holds $F$ distribution, and $\mathrm{F}$ test is suggested for coeffi- 
cient test because of its better small properties [15] [21] [24]. If the testing result rejects the null hypothesis of $H_{1}$, it indicates that the nonlinear model should be selected to describe the relationship between variables. Subsequently, we can select an appropriate nonlinear model via doing three types of coefficient tests, all of which contain $F$ distribution. The three coefficient tests extended from the null hypothesis are as the following:

$$
\begin{gathered}
H_{2}: \beta_{1}^{\prime}=0 \mid \beta_{2}^{\prime}=\beta_{3}^{\prime}=0 \\
H_{3}: \beta_{2}^{\prime}=0 \mid \beta_{3}^{\prime}=0 \\
H_{4}: \beta_{3}^{\prime}=0
\end{gathered}
$$

If the testing result shows that the rejection of $\mathrm{H}_{3}$ is the strongest, the appropriate nonlinear model is either the LSTR2 model or the exponential smooth transition regression model (ESTR), either of which should be chosen by doing the null hypothesis test of $H_{0}: c_{1}=c_{2}$. If $H_{0}$ is not rejected, it means that there should be one regime switch, and the optimal model will be the ESTR model; otherwise, the appropriate model will be the LSTR2 model. However, if the testing result indicates that the rejection of $\mathrm{H}_{2}$ or $\mathrm{H}_{4}$ is the strongest, the appropriate nonlinear model will be the logistic smooth transition regression model with one regime switch (LSTR).

Once the linear model is rejected, the next step is to select the appropriate transition variable and estimate the parameters of transition function. Teräsvirta [15] suggested the transition function $F\left(s_{t}, \gamma, c\right)$ should be standardized to make $\gamma$ scale-free, which means dividing the exponent in $F\left(s_{t}, \gamma, c\right)$ by the standard deviation of $s_{t}$, as the expression of Equation (11) shows.

$$
F\left(s_{t}, \gamma, c\right)=\left(1+\exp \left\{-\frac{\gamma}{\widehat{\sigma_{s_{t}}}}\left(s_{t}-c\right)\right\}\right)^{-1}
$$

A grid search method is employed here to find the parameter $\gamma$ and $c$, and the model with the minimum value of the sum of square residuals (SSR) from the grid search method will be used to provide an initial value of $\gamma$ and $c$ for the initial estimation of the STR model.

\subsection{Empirical Model}

Therefore, we establish a smooth transition regression model to describe the nonlinear relationship between electricity consumption and temperature. Considering the assumption of exogeneity for electricity consumption to temperature, Chen et al. [25] examined the relationship of Granger causality between energy consumption and $\mathrm{CO}_{2}$ emissions using the data of 188 countries, and they only observed the unidirectional causality from energy consumption to $\mathrm{CO}_{2}$ emissions. Chang [26] also suggested the unidirectional causality from electricity consumption to $\mathrm{CO}_{2}$ emissions. Therefore, we can say that the increasing electricity consumption directly causes the rising of $\mathrm{CO}_{2}$ emissions, indirectly leads to higher average temperature caused by global warming, and electricity con- 
sumption further increases again directly due to the higher average temperature. In short, electricity consumption could indirectly affect temperature through climate change in the long term, and in turn, temperature can directly affect electricity consumption [27]. That is, we can estimate the STR models under the assumption of exogeneity. Hence, our empirical model is written as Equation (12),

$$
\begin{aligned}
\text { FEC }_{t}= & \pi_{0}+\pi_{1} \sum_{i=1}^{p} F E C_{t-i}+\pi_{2} \text { TEMP }_{t} \\
& +F\left(T E M P_{t}, \gamma, c\right)\left(\theta_{1} \sum_{i=1}^{p} F E C_{t-i}+\theta_{2} T^{2} M P_{t}\right)+u_{t}
\end{aligned}
$$

where $t$ means time dimension; $F E C_{t}$ represents filtered electricity consumption at time $t ; T E M P_{t}$ denotes temperature at time $t ; u_{t}$ stands for the residuals with a mean of zero and constant variance; $F\left(T E M P_{t}, \gamma, c\right)$ is the transition function with the transition variable $T E M P_{t}$. As mentioned before, the parameters of $\gamma, \mathcal{c}$, $\pi_{2}$, and $\theta_{2}$ are the key parameters of our following estimation.

\section{Estimated Results}

\subsection{Unit Root Testing}

Before performing the unit root testing, we divide the samples into six sample groups, and the sample period is four years for each sample group. Table 3 reports the results of unit testing for each data series. We can see that the series $F E C_{t}$ is stationary for each sample period from the results of ADF test and P.P. test. On the other hand, the results of ADF test and P.P. test for TEMP $P_{t}$ are similar to the testing results of the series $F E C_{t}$ which rejects the null hypothesis of unit root. This means that the series $F E C_{t}$ is stationary for each sample period.

When we considers the DGP of series with possible structural breaks, the impulse dummy and shift dummy are used to detect possible structural breaks in this study. The result of unit root testing for structural breaks shows that all the null hypothesis of unit root is rejected at $1 \%$ significance level no matter the series are $F E C_{t}$ or TEMP $P_{t}$ while the DGP of series includes impulse dummy variables for structural breaks, meaning all series are stationary for each sample period. However, when the DGP of series includes shift dummy variables for structural breaks, some reject the null hypothesis, others do not.

In sum, we conclude that both the series $F E C_{t}$ and the series TEMP $P_{t}$ are stationary at level based on our unit root testing; that is, we will estimate the empirical model with level data.

\subsection{Estimated Result of the STR Model}

Table 4 shows the results of the nonlinear model test for each sample period, $F_{1}$, $F_{2}, F_{3}$ and $F_{4}$ represent the statistic of $F$ test for $H_{1}, H_{2}, H_{3}$ and $H_{4}$, respectively. Firstly, we can see that the P-value of $F_{1}$ for each period all reject the null hypothesis of the linear model at $1 \%$ significance level, meaning that we should consider the nonlinear relationship between electricity consumption and temperature in our empirical model for each sample period. Secondly, as the rules of 
model selection mentioned before indicates, if $F_{2}$ or $F_{4}$ has the strongest significant P-value among $F_{2}, F_{3}$ and $F_{4}$, the appropriate model will be LSTR. Moreover, the testing results indicate that the appropriate models of each sample period are all LSTR models.

Table 3. Results of unit root test.

\begin{tabular}{|c|c|c|c|c|c|c|c|}
\hline \multirow[b]{2}{*}{ Variables } & \multirow[b]{2}{*}{ Intercept } & \multicolumn{2}{|c|}{ ADF test } & \multicolumn{2}{|c|}{ P.P. test } & \multicolumn{2}{|c|}{ UR test with structural break } \\
\hline & & Intercept \& Trend & Intercept & Intercept \& Trend & Impulse dummy & Shift dummy & Break point \\
\hline \multicolumn{8}{|c|}{ Sample period: $1983-1987$} \\
\hline$F E C_{t}$ & $-8.053^{* * *}$ & $-8.088^{\star * *}$ & $-8.057^{\star * *}$ & $-8.093^{* * *}$ & $-4.230^{\star * *}$ & -2.209 & $1986 \mathrm{M} 08$ \\
\hline$\triangle F E C_{t}$ & $-14.067^{\star * *}$ & $-14.076^{\star * *}$ & $-31.987^{\star * *}$ & $-31.258^{* * *}$ & $-5.543^{\star * *}$ & $-4.344^{* * *}$ & 1986M08 \\
\hline$T E M P_{t}$ & $-6.775^{\star * *}$ & $-6.868^{\star * *}$ & $-3.328^{\star *}$ & $-3.259^{*}$ & $-7.441^{\star * *}$ & $-7.267^{\star * *}$ & 1987M09 \\
\hline$\triangle T E M P_{t}$ & $-9.803^{* * *}$ & $-9.839^{* * *}$ & $-3.331^{\star *}$ & $-3.332^{*}$ & $-3.824^{\star * *}$ & -2.468 & 1985M04 \\
\hline \multicolumn{8}{|c|}{ Sample period: $1988-1992$} \\
\hline$F E C_{t}$ & $-6.753^{* * *}$ & $-6.621^{\star * *}$ & $-5.044^{* * \star}$ & $-5.002^{\star * *}$ & $-3.956^{\star * *}$ & -2.053 & 1991M06 \\
\hline$\triangle F E C_{t}$ & $-15.562^{\star * \star}$ & $-15.676^{\star * *}$ & $-11.551^{\star * *}$ & $-11.466^{\star * *}$ & $-4.604^{\star \star \star}$ & -1.657 & 1991M03 \\
\hline$T E M P_{t}$ & $-10.332^{\star * *}$ & $-10.209^{\star * *}$ & $-3.297^{\star *}$ & $-3.229^{*}$ & $-8.178^{\star \star \star}$ & $-7.026^{\star * *}$ & 1989M04 \\
\hline$\triangle T E M P_{t}$ & $-6.323^{\star * *}$ & $-6.260^{\star * \star}$ & $-4.139^{\star * \star}$ & $-4.143^{\star * \star}$ & $-4.687^{\star \star \star}$ & $-4.753^{\star * \star}$ & 1988M06 \\
\hline \multicolumn{8}{|c|}{ Sample period: 1993-1997 } \\
\hline$F E C_{t}$ & $-6.279^{* * *}$ & $-6.638^{\star * \star}$ & $-4.692^{\star * \star}$ & $-4.645^{\star \star \star}$ & $-4.880^{\star * \star}$ & $-3.461^{\star \star}$ & 1996M08 \\
\hline$\triangle F E C_{t}$ & $-12.341^{\star * *}$ & $-12.315^{\star \star \star}$ & $-11.494^{\star * \star}$ & $-11.397^{\star \star \star}$ & $-4.882^{\star * \star}$ & -2.163 & 1997M03 \\
\hline$T E M P_{t}$ & $-8.058^{\star * \star}$ & $-8.064^{\star \star \star}$ & $-3.286^{\star \star}$ & $-3.234^{\star}$ & $-7.945^{\star \star \star}$ & $-5.224^{\star * \star}$ & 1994M04 \\
\hline$\triangle T E M P_{t}$ & $-7.564^{* * *}$ & $-7.482^{\star * \star}$ & $-4.126^{\star * \star}$ & $-4.118^{\star * \star}$ & $-4.357^{\star * *}$ & $-3.201^{* * *}$ & 1994M04 \\
\hline \multicolumn{8}{|c|}{ Sample period: $1998-2002$} \\
\hline$F E C_{t}$ & $-6.595^{\star * *}$ & $-6.564^{\star * *}$ & $-3.832^{\star * *}$ & $-3.812^{\star *}$ & $-4.928^{\star * *}$ & $-3.510^{\star * *}$ & $2001 \mathrm{M} 11$ \\
\hline$\triangle F E C_{t}$ & $-8.943^{* * *}$ & $-8.851^{\star * *}$ & $-9.738^{\star * *}$ & $-9.655^{\star * *}$ & $-4.109^{* * *}$ & -1.229 & $2002 \mathrm{M} 03$ \\
\hline$T E M P_{t}$ & $-6.359^{\star * *}$ & $-6.294^{\star * *}$ & $-3.248^{\star *}$ & $-3.182^{\star}$ & $-8.225^{\star * *}$ & $-6.902^{\star * *}$ & 1999M12 \\
\hline$\triangle T E M P_{t}$ & $-8.201^{\star * *}$ & $-8.117^{\star * *}$ & $-3.672^{\star * \star}$ & $-3.680^{* *}$ & $-5.312^{\star * \star}$ & $-3.349^{* * *}$ & 2000M01 \\
\hline \multicolumn{8}{|c|}{ Sample period: $2003-2007$} \\
\hline$F E C_{t}$ & $-6.435^{\star * *}$ & $-7.440^{\star \star \star}$ & $-3.921^{\star \star \star}$ & $-3.959^{\star \star}$ & $-4.890^{\star * \star}$ & $-4.251^{\star \star \star}$ & 2005M02 \\
\hline$\triangle F E C_{t}$ & $-12.405^{\star * *}$ & $-12.321^{\star * *}$ & $-9.717^{\star * *}$ & $-9.644^{* * *}$ & $-3.701^{\star * *}$ & -1.653 & 2005M03 \\
\hline$T E M P_{t}$ & $-8.715^{\star * \star}$ & $-9.082^{\star * *}$ & $-3.267^{\star *}$ & $-3.204^{\star}$ & $-8.328^{\star * *}$ & $-5.063^{* * *}$ & $2005 \mathrm{M} 12$ \\
\hline$\Delta T E M P_{t}$ & $-8.867^{* * *}$ & $-8.895^{\star \star \star}$ & $-4.381^{\star \star \star}$ & $-4.375^{\star * \star}$ & $-4.133^{\star * *}$ & $-3.844^{\star * \star}$ & $2005 \mathrm{M} 12$ \\
\hline \multicolumn{8}{|c|}{ Sample period: $2008-2012$} \\
\hline$F E C_{t}$ & $-6.435^{* * *}$ & $-7.440^{* * *}$ & $-3.921^{\star * \star}$ & $-3.959^{* *}$ & $-3.480^{* * *}$ & $-2.997^{* *}$ & 2008M11 \\
\hline$\triangle F E C_{t}$ & $-12.405^{\star * *}$ & $-12.321^{\star * *}$ & $-9.717^{\star \star \star}$ & $-9.644^{\star * *}$ & $-3.634^{\star * *}$ & -1.508 & 2012M03 \\
\hline$T E M P_{t}$ & $-8.715^{\star * \star}$ & $-9.082^{\star * \star}$ & $-3.267^{\star *}$ & $-3.204^{\star}$ & $-9.686^{\star * *}$ & $-6.938^{\star * \star}$ & 2009M02 \\
\hline$\Delta T E M P_{t}$ & $-8.867^{* * *}$ & $-8.895^{\star * *}$ & $-4.381^{\star \star \star}$ & $-4.375^{\star * \star}$ & $-5.231^{\star * *}$ & $-3.596^{\star * *}$ & 2009M02 \\
\hline
\end{tabular}

Notes: 1 ) The critical values $(1 \%, 5 \%, 10 \%)$ of UR test with structural break are $(-3.48,-2.88,-2.58) .2)^{\star * *}$, ${ }^{* *}$, refers to the significance level at $1 \%, 5 \%$, $10 \%$, respectively. 
Table 4. Results of appropriate nonlinear model test.

\begin{tabular}{cccccc}
\hline Sample period & $F_{1}$ & $F_{4}$ & $F_{3}$ & $F_{2}$ & Selected model \\
\hline $1983-1987$ & 0.000 & 0.235 & 0.044 & $0.000^{*}$ & LSTR \\
$1988-1992$ & 0.000 & 0.682 & 0.001 & $0.000^{*}$ & LSTR \\
$1993-1997$ & 0.000 & $0.000^{*}$ & 0.001 & 0.007 & LSTR \\
$1998-2002$ & 0.010 & 0.463 & 0.638 & $0.000^{*}$ & LSTR \\
$2003-2007$ & 0.000 & $0.004^{*}$ & 0.030 & 0.053 & LSTR \\
$2008-2012$ & 0.007 & 0.248 & 0.136 & $0.002^{*}$ & LSTR \\
\hline
\end{tabular}

Notes: ${ }^{\star}$ denotes the strongest rejection among null hypothesis of $H_{2}, H_{3}$ and $H_{4}$.

Table 5. The estimated results of STR models.

\begin{tabular}{|c|c|c|c|c|c|c|}
\hline \multirow{2}{*}{ Estimated results } & \multicolumn{6}{|c|}{ Sample period } \\
\hline & 1983-1987 & $1988-1992$ & 1993-1997 & $1998-2002$ & $2003-2007$ & $2008-2012$ \\
\hline \multicolumn{7}{|c|}{ The linear part of the model } \\
\hline$\pi_{2}$ & $3.756(0.944)^{\star * *}$ & $3.774(1.105)^{\star * \star}$ & $4.527(1.463)^{\star \star *}$ & $9.313(1.135)^{\star * *}$ & $18.485(3.308)^{\star * *}$ & $23.128(4.080)^{\star \star *}$ \\
\hline \multicolumn{7}{|c|}{ The nonlinear part of the model } \\
\hline$\theta_{2}$ & $25.225(7.404)^{\star * *}$ & $15.119(7.272)^{\star *}$ & $11.682(23.677)$ & $42.108(46.399)$ & $4.536(2.359)^{*}$ & $9.375(6.552)$ \\
\hline$\gamma$ & $39.400(22.385)^{\star}$ & $6.843(2.968)^{\star *}$ & $7.464(4.378)^{\star}$ & $15.396(6.739)^{\star *}$ & $4.088(2.707)$ & $6.271(4.657)$ \\
\hline$c$ & $26.892(0.222)^{\star * *}$ & $25.530(0.624)^{\star * *}$ & $25.364(0.459)^{\star * *}$ & $27.156(0.421)^{\star * *}$ & $26.477(0.802)^{\star * *}$ & $26.884(0.771)^{\star * *}$ \\
\hline $\mathrm{SD}$ of residuals & 8.511 & 10.119 & 12.452 & 20.391 & 27.474 & 32.726 \\
\hline AIC & 4.564 & 4.893 & 5.681 & 6.278 & 6.806 & 7.643 \\
\hline NO. of observations & 53 & 53 & 53 & 52 & 54 & 53 \\
\hline
\end{tabular}

Notes: $1{ }^{* * *},{ }^{* *},{ }^{*}$ refers to the significance level at $1 \%, 5 \%, 10 \%$, respectively. 2$)$ () refers to stand error.

Subsequently, we establish the LSTR model for six sample periods, respectively. Table 5 represents the estimated results of the STR model for each sample periods, the appropriate lag length of the dependent variable is chosen by minimum AIC (Akaike Information Criterion) with maximum lag length of 10 lags. We only report the estimated coefficient of key parameters in Table 5 to focus on threshold temperature of electricity consumption.

We can see that the estimated results of the linear part of all models indicate the positively significant relationships exist between electricity consumption and temperature in Taiwan. Furthermore, the largest coefficient of $\pi_{2}$ is estimated during the period from 2003 to 2007 (Model 5), meaning that during these 5 years, when temperature increases by $1^{\circ} \mathrm{C}$, people are the most sensitive to consume excessive electricity compared with other periods.

In addition, for the estimated results of the nonlinear part, Model 2, Model 3 and Model 6 represents the positively significant relationships also exist between electricity consumption and temperature. It implies that when the transition va- 
riable (temperature) increases, the relationship between electricity consumption and temperature becomes much more positive.

Turning to the slope parameter $\gamma$, the estimated values are from 4.088 to 39.400 , and four of six models provide the significant value of parameter $\gamma$, in addition, for the estimated results of parameter $c$, the estimated values are from $25.530^{\circ} \mathrm{C}$ to $27.156^{\circ} \mathrm{C}$, which implies that the electricity consumption is continuously transforming with logistic function when the temperature level reaches an inflexion point. For instance, as the result of Model 6, when the temperature reaches $26.884^{\circ} \mathrm{C}$, the relationship between electricity consumption and temperature becomes more sensitive, and increases in temperature cause nonlinear increases in electricity consumption.

At this level, we can make three remarks. Firstly, the estimated value of threshold parameter $c\left(25.530^{\circ} \mathrm{C}\right.$ to $\left.27.156^{\circ} \mathrm{C}\right)$ is different from the value of $18.3^{\circ} \mathrm{C}$ generally used as the reference temperature of cooling degree days (CDDs) in the past literatures. Secondly, the average of all threshold value is $26.384^{\circ} \mathrm{C}$, and this value is not only close to the official reference temperature of CDDs in Taiwan, but also similar to the threshold temperature of CDDs used by Holtedahl and Joutz [28] $\left(74^{\circ} \mathrm{F}\right.$ and $\left.80^{\circ} \mathrm{F}\right)$. Thirdly, the threshold value of temperature is not always a fixed value; the number could fluctuate in different time periods.

Moreover, we can reasonably infer that El Nino Southern Oscillation (ENSO) is one of the reasons for varying threshold temperatures in different time periods. We believe that El Niño events will lead to warmer winters and hotter summers; that is, there will be more hot days in a year when an El Niño event occurs. Needless to say, more hot days could change how people use electricity. For instance, as an El Niño event makes people feel hot in a warmer winter, people would use air-conditioners to create a comfortable indoor temperature by lowering the temperature, which leads to a lower the threshold temperature. On the contrary, a La Niña event makes colder summers and winters colder, which would also encourage people to use air-conditioner due to a higher temperature; this could lead to a higher threshold temperature.

To add this into consideration, we define ENSO score based on the data of Oceanic Niño Index (ONI) sourced from CPC [29]. According to the definition of ENSO events, we assign a score of 4 to -4 to distinguish a very strong El Niño year (a score 4), a strong El Niño year (a score 3), a moderate El Niño year (a score 2), a weak El Niño year (a score 1), a neutral year (a score 0 ), a weak La Niña year (a score -1 ), a moderate La Niña year (a score -2 ), and -3 for a strong La Niña year (a score -3 ). Therefore, we can see the relationship between ENSO scores and threshold temperatures from Figure 3.

\subsection{Model Diagnostics}

The quality of the estimated nonlinear model would be examined against misspecification like what we conducted on the linear model. Specification tests such as the serial correlation test [30], the ARCH-LM test [31], a normality test, a parameter constancy test and the no remaining nonlinearity test are employed for 


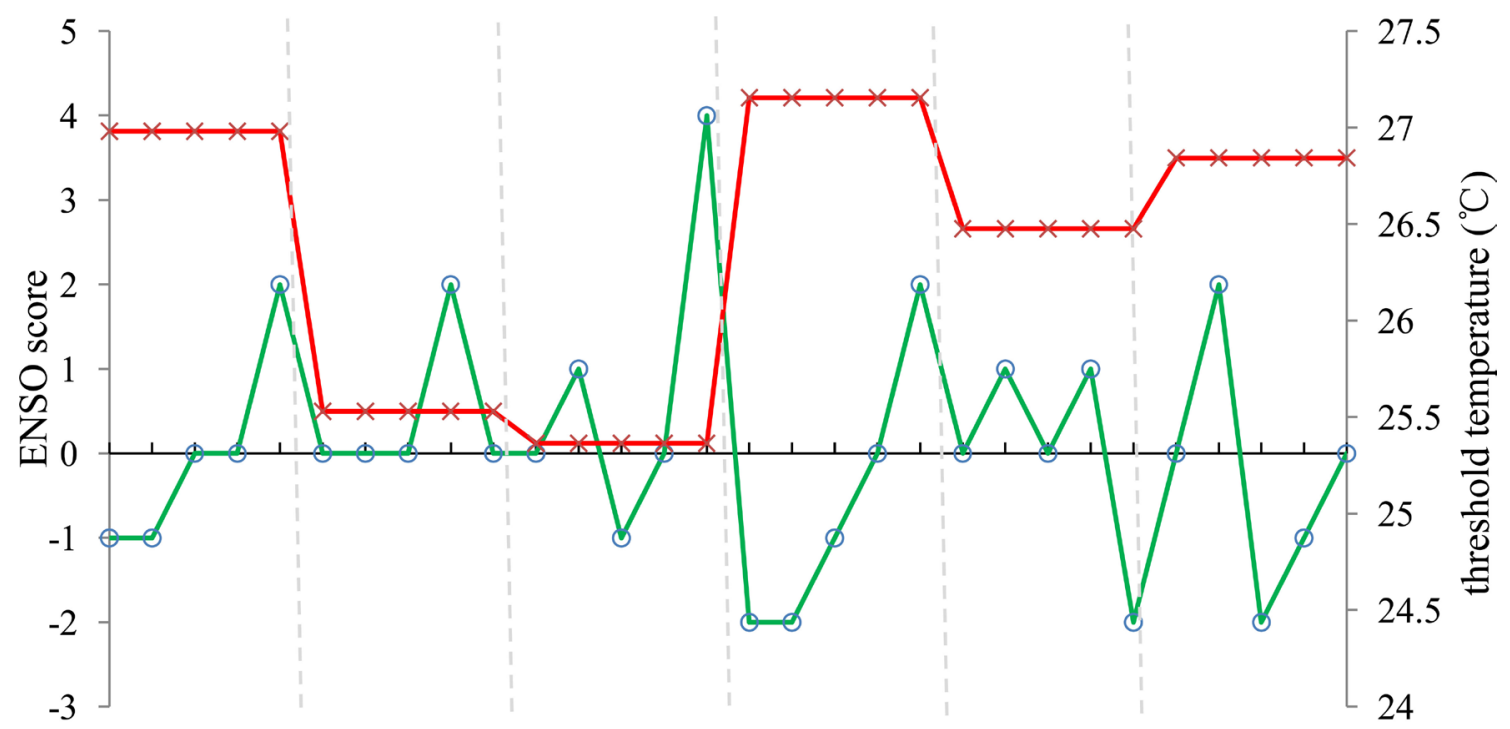

ฌ

$\multimap$ ENSO Score $\quad *$ Threshold Temperature

Figure 3. Historical ENSO score and threshold temperature.

Table 6. Testing for the serial autocorrelation of residuals (F-value).

\begin{tabular}{ccccccccc}
\hline Lag & 1 & 2 & 3 & 4 & 5 & 6 & 7 & 8 \\
\hline Model 1 & 2.149 & 1.605 & 1.493 & 1.008 & 1.399 & 1.195 & 1.500 & 1.232 \\
Model 2 & 1.905 & 2.054 & 1.472 & $2.682^{\star}$ & 2.034 & 1.787 & 1.720 & 1.467 \\
Model 3 & 0.875 & 0.731 & 0.945 & 0.939 & 0.875 & 0.728 & 0.577 & 0.450 \\
Model 4 & 1.159 & 1.377 & 0.685 & 0.619 & 0.687 & 0.895 & 0.809 & 0.651 \\
Model 5 & 0.205 & 0.318 & 0.964 & 0.671 & 0.695 & 0.576 & 1.171 & 1.038 \\
Model 6 & 1.716 & 0.928 & 1.354 & 0.942 & 0.719 & 0.820 & 0.689 & 0.599 \\
\hline
\end{tabular}

Notes: ${ }^{\star}$ refers to the significance level at $10 \%$.

model diagnostic in this section. Table 6 shows the testing results of the serial correlation of residuals for each model with 8 lag terms. We can see that only the fourth lag term of Model 2 rejects the null hypothesis of no serial correlation of residuals at $10 \%$ significance level. Overall, we can say that none of six models have the serial correlation.

In addition, Table 7 reports the testing results of the ARCH-LM test, the normality test, the parameter constancy test and the no remaining nonlinearity test, respectively. We can see that all models are no problem of heteroskedasticity up to the lag order of eight as the results of the ARCH-LM test. All results of the Jarque-Bera (J.B.) normality test cannot reject the null hypothesis of normality, meaning that the error terms of all models are normally distributed.

We also check whether there is remaining nonlinearity in the models after all the STR models has been fitted, and the null hypothesis of no remaining nonlinearity test is no additive nonlinearity of the STR model. The testing results are 
all statistically non-significant, which means there is no additive nonlinearity in any of the STR model. The null hypothesis of parameter constancy test is constant parameters against the alternative hypothesis of smooth continuous changes in parameters. The testing results cannot reject the null hypothesis, and it indicates that the parameters of six models are constant in both regimes.

Figure 4 graphs logistic transition function of six models, and the diagram of Model 1 to Model 6 are listed in Figure 4 from left to right and from up to down. We can see that Model 1 has the steepest slope of logistic transition function among the six models, meaning the speed of its transition between two regimes is the fastest during the period from 1983 to 1988. By contrast, Model 5 has the gentlest slope of logistic transition function among the six models, showing that the speed of its transition between the two regimes is the slowest during the period from 2003 to 2007.

Table 7. Results of specification tests.

\begin{tabular}{lcccc}
\hline & $\begin{array}{c}\text { ARCH-LM test } \\
\left(x^{2}[8]\right)\end{array}$ & $\begin{array}{c}\text { Normality test } \\
\text { (J.B.) }\end{array}$ & $\begin{array}{c}\text { No remaining nonlinearity } \\
\text { test (P-value) }\end{array}$ & $\begin{array}{c}\text { Parameter constancy test } \\
\text { (F-value) }\end{array}$ \\
\hline Model 1 & 3.497 & 0.499 & 0.513 & 1.432 \\
Model 2 & 8.553 & 4.341 & 0.667 & 0.388 \\
Model 3 & 8.174 & 0.196 & 0.644 & 0.913 \\
Model 4 & 6.597 & 1.996 & 0.993 & 1.463 \\
Model 5 & 7.733 & 1.135 & 0.838 & 1.671 \\
Model 6 & 13.026 & 1.284 & 0.856 & 0.349 \\
\hline
\end{tabular}
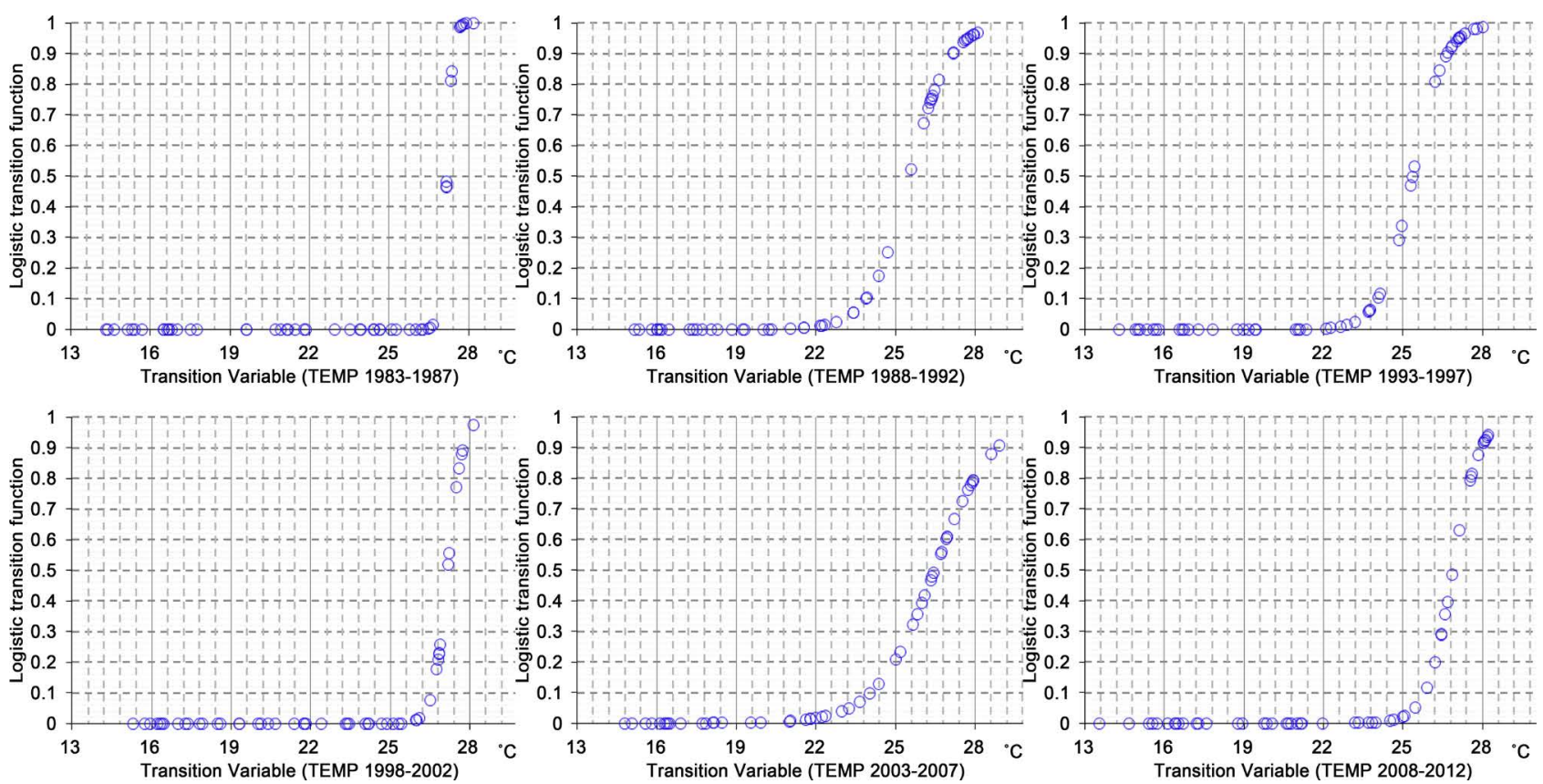

Source: Author's estimation.

Figure 4. Logistic transition function of six models which all are with transition variable of temperature. 


\section{Conclusions}

This study discusses the relationship between electricity consumption and temperature in Taiwan for the period from 1983 to 2012. In order to get more information from our data, we divide all samples into six groups with sample period of five years for each group before conducting the empirical estimation. Furthermore, we employ the STR model to estimate the nonlinear relationship between electricity consumption and temperature for each sample period. In addition, we also find threshold temperatures on the nonlinear relationship between electricity consumption and temperature for each sample period.

The empirical results show that there are positively significant effects of temperature on electricity consumption in Taiwan for each sample period. When we only focus on the estimated results for the linear part of the model, we can find that the purely linear effects of temperature on electricity consumption keep rising over the whole sample period. However, some estimated results for the nonlinear part of the model are positively significant, while others are not. That is, we cannot conclude that the purely total effects of temperature on electricity consumption also keep magnifying over the whole sample period.

On the other hand, we figure out the threshold temperature estimated using the STR estimation for each sample period. The threshold temperature is $26.892^{\circ} \mathrm{C}$ (1983-1987), $25.530^{\circ} \mathrm{C}$ (1988-1992), $25.364^{\circ} \mathrm{C}$ (1993-1997), $27.156^{\circ} \mathrm{C}$ (1998-2002), $26.477^{\circ} \mathrm{C}(2003-2007)$, and $26.884^{\circ} \mathrm{C}(2008-2012)$. In sum, the average threshold temperature over the period from 1983 to 2012 is $26.384^{\circ} \mathrm{C}$. We can say that the pure effects of temperature on electricity become much more sensitive if temperature reaches the threshold temperature based on our empirical results. In addition, Taiwan has a subtropical climate with higher humidity and a higher yearly average temperature (at about $22^{\circ} \mathrm{C}$ ), meaning that Taiwan has a higher temperature compared to other countries with a temperate and frigid climate. Hence, estimated temperatures in this study are between $25^{\circ} \mathrm{C}$ and $27^{\circ} \mathrm{C}$, which are reasonably comfortable for people living in subtropical climate such as Taiwan. Furthermore, the estimated threshold temperature carries the same meaning with the reference temperature of CDDs. That is, if the air temperature is higher than the threshold temperature, it will lead to increases in electricity consumption. For instance, policy makers could use the threshold temperature to be the reference temperature, and thus they could propose a policy to ask people to reduce electricity consumption when the air temperature is higher than the reference temperature in order to save electricity and to promote efficiency of using electricity.

In addition, increasing use of air conditioning resulted in temperature rise for a comfortable living environment seems to be a serious problem of power supply in Taiwan under the influence of global warming. Santamouris et al. [32] concluded that a $1 \%$ increase in temperature under the threshold temperature of $24^{\circ} \mathrm{C}$ in warm countries would lead to a $3.5 \%$ increase in peak electricity demand. That is, if the ambient temperature is higher than the threshold temperature, the 
risk of power shortage sharply rises. Now Taiwan is aiming for a future of a non-nuclear homeland and is actively developing renewable energy (mainly wind and solar power) to meet the estimated losses of nuclear energy. However, wind and solar power are not stable sources of power supply due to current limitations of power storage technology in Taiwan. Therefore, the threshold temperature could send a warning signal to not only promote the idea of energy saving but also suggest more power system expansion planning in preparation for more operating reserve in the future.

Thus, the estimated threshold temperature will have policy implications for policy makers, who can use the threshold temperature in this study as a reference for making electricity management policies in Taiwan.

\section{References}

[1] Mideksa, T.K. and Kallbekken, S. (2010) The Impact of Climate Change on the Electricity Market: A Review. Energy Policy, 38, 3579-3585. https://doi.org/10.1016/j.enpol.2010.02.035

[2] Ruth, M. and Lin, A.C. (2006) Regional Energy Demand and Adaptations to Climate Change: Methodology and Application to the State of Maryland, USA. Energy Policy, 34, 2820-2833. https://doi.org/10.1016/j.enpol.2005.04.016

[3] Parkpoom, S. and Harrison, G.P. (2008) Analyzing the Impact of Climate Change on Future Electricity Demand in Thailand. IEEE Transactions on Power Systems, 23, 1441-1448. https://doi.org/10.1109/TPWRS.2008.922254

[4] Howden, S. M. and Crimp, S. (2001) Effect of Climate and Climate Change on Electricity Demand in Australia. CSIRO Sustainable Ecosystem.

[5] Ahmed, T., Muttaqi, K.M. and Agalgaonkar, A.P. (2012) Climate Change Impacts on Electricity Demand in the State of New South Wales, Australia. Applied Energy, 98, 376-383. https://doi.org/10.1016/j.apenergy.2012.03.059

[6] Zachariadis, T. and Hadjinicolaou, P. (2014) The Effect of Climate Change on Electricity Needs-A Case Study from Mediterranean Europe. Energy, 76, 899-910. https://doi.org/10.1016/j.energy.2014.09.001

[7] Benestad, R. (2008) Heating Degree Days, Cooling Degree Days, and Precipitation in Europe: Analysis for the CELECT-Project. Report for Norwegian Metting.

[8] De Cian, E., Lanzi, E. and Roson, R. (2007) The Impact of Temperature Change on Energy Demand: A Dynamic Panel Analysis. Working Papers 2007.46, Fondazione Eni Enrico Mattei, Milan.

[9] Hekkenberg, M., Moll, H.C. and Schoot-Uiterkamp, A.J.M. (2009) Dynamic Temperature Dependence Patterns in Future Energy Demand Models in the Context of Climate Change. Energy, 34, 1797-1806. https://doi.org/10.1016/j.energy.2009.07.037

[10] Moral-Carcedo, J. and Vicéns-Otero, J. (2005) Modelling the Non-Linear Response of Spanish Electricity Demand to Temperature Variations. Energy Economics, 27, 477-494. https://doi.org/10.1016/j.eneco.2005.01.003

[11] Bessec, M. and Fouquau, J. (2008) The Non-linear Link between Electricity Consumption and Temperature in Europe: A Threshold Panel Approach. Energy Economics, 30, 2705-2721. https://doi.org/10.1016/j.eneco.2008.02.003

[12] Lee, C.C. and Chiu, Y.B. (2011) Electricity Demand Elasticities and Temperature: Evidence from Panel Smooth Transition Regression with Instrumental Variable 
Approach. Energy Economics, 33, 896-902. https://doi.org/10.1016/j.eneco.2011.05.009

[13] MOEABOE (2015) Energy Statistical Hand Book 2014. Bureau of Energy, Ministry of Economic Affairs, Taiwan.

[14] TCCIP (2014) TCCIP Data Service Platform, Taiwan Climate Change Projection and Information Platform. Ministry of Science and Technology, Executive Yuan, Taiwan. https://tccip.ncdr.nat.gov.tw/v2/index_en.aspx

[15] Teräsvirta, T. (1994) Specification Estimation and Evaluation of Smooth Transition Autoregressive Models. Journal of the American Statistical Association, 89, 208-218.

[16] Dickey, D.A. and Fuller, W.A. (1979) Estimators for Autoregressive Time Series with a Unit Root. Journal of the American Statistical Association, 74, 427-431.

[17] Phillips, P.C.B. and Perron, P. (1988) Testing for a Unit Root in Time Series Regression. Biometrika, 75, 335-346. https://doi.org/10.1093/biomet/75.2.335

[18] Saikkonen, P. and Lütkepohl, H. (2002) Testing for a Unit Root in a Time Series with a Level Shift at Unknown Time. Econometric Theory, 18, 313-348. https://doi.org/10.1017/S0266466602182053

[19] Lanne, M., Lütkepohl, H. and Saikkonen, P. (2002) Comparison of Unit Root Tests for Time Series with Level Shifts. Journal of Time Series Analysis, 23, 667-685. https://doi.org/10.1111/1467-9892.00285

[20] Chan, K.S. and Tong, H. (1986) On Estimating Thresholds in Autoregressive Models. Journal of Time Series Analysis, 7, 179-190. https://doi.org/10.1111/j.1467-9892.1986.tb00501.x

[21] Luukkonen, R., Saikkonen, P. and Teräsvirta, T. (1988) Testing Linearity against Smooth Transition Autoregressive Models. Biometrika, 75, 491-499. https://doi.org/10.1093/biomet/75.3.491

[22] Teräsvirta, T. (1998) Modelling Economic Relationships with Smooth Transition Regression. In: Ullah, A. and Giles, D., Eds., Handbook of Applied Economic Statistics, Marcel Dekker, New York, 229-246.

[23] Areosa, W.D., McAleer, M. and Medeiros, C.M. (2011) Moment-Based Estimation of Smooth Transition Regression Models with Endogenous Variables. Journal of Econometrics, 165, 100-111. https://doi.org/10.1016/j.jeconom.2011.05.009

[24] Teräsvirta, T. (2004) Smooth Transition Regression Modelling. In: Lütkepoh, H. and Krätzig, M., Eds., Applied Time Series Econometrics, Cambridge University Press, Cambridge, 222-242. https://doi.org/10.1017/CBO9780511606885.007

[25] Chen, P.Y., Chen, S.T., Hsu, C.S. and Chen, C.C. (2016) Modeling the Global Relationships among Economic Growth, Energy Consumption and $\mathrm{CO}_{2}$ Emissions. Renewable and Sustainable Energy Reviews, 65, 420-431. https://doi.org/10.1016/j.rser.2016.06.074

[26] Chang, C.C. (2010) A Multivariate Causality Test of Carbon Dioxide Emissions, Energy Consumption and Economic Growth in China. Applied Energy, 87, 3533-3537. https://doi.org/10.1016/j.apenergy.2010.05.004

[27] Hao, Y., Chen, H., Wei, Y.M. and Li, Y.M. (2016) The Influence of Climate Change on $\mathrm{CO}_{2}$ (Carbon Dioxide) Emissions: An Empirical Estimation Based on Chinese Provincial Panel Data. Journal of Cleaner Production, 131, 667-677. https://doi.org/10.1016/j.jclepro.2016.04.117

[28] Holtedahl, P. and Joutz, F.L. (2004) Residential Electricity Demand in Taiwan. Energy Economics, 26, 201-224. https://doi.org/10.1016/j.eneco.2003.11.001

[29] CPC (2015) Climate Prediction Center, National Oceanic and Atomspheric Admin- 
istration, USA.

http://www.cpc.noaa.gov/products/analysis_monitoring/ensostuff/ensoyears.shtml

[30] Godfrey, L. (1988) Misspecification Tests in Econometrics. Cambridge University Press, Cambridge.

[31] Engle, R.F. (1982) Autoregressive Conditional Heteroscedasticity with Estimates of the Variance of United Kingdom Inflation. Econometrica, 50, 987-1007. https://doi.org/10.2307/1912773

[32] Santamouris, M., Cartalis, C., Synnefa, A. and Kolokotsa, D. (2015) On the Impact of Urban Heat Island and Global Warming on the Power Demand and Electricity Consumption of Buildings-A Review. Energy and Buildings, 98, 119-124.

https://doi.org/10.1016/j.enbuild.2014.09.052 